\title{
Two millennia of Main region (southern Germany) hydroclimate variability
}

\author{
Alexander Land $^{1,2}$, Sabine Remmele ${ }^{1,2}$, Jutta Hofmann ${ }^{3}$, Daniel Reichle ${ }^{1}$, Margaret Eppli ${ }^{1}$, Christian Zang ${ }^{4}$, \\ Allan Buras ${ }^{5}$, Sebastian Hein ${ }^{2}$, and Reiner Zimmermann ${ }^{1}$ \\ ${ }^{1}$ University of Hohenheim, Institute of Botany (210a), Garbenstraße 30, 70599 Stuttgart, Germany \\ ${ }^{2}$ University of Applied Forest Sciences, Schadenweilerhof, 72108 Rottenburg am Neckar, Germany \\ ${ }^{3}$ Jahrringlabor Hofmann, Waldhäuser Str. 12, 72622 Nürtingen, Germany \\ ${ }^{4}$ Technical University of Munich, Land Surface-Atmosphere Interactions, Hans-Carl-von-Carlowitz-Platz 2, \\ 85354 Freising, Germany \\ ${ }^{5}$ Technical University of Munich, Ecoclimatology, Hans-Carl-von-Carlowitz-Platz 2, 85354 Freising, Germany
}

Correspondence: Alexander Land (alexander.land@uni-hohenheim.de)

Received: 23 October 2018 - Discussion started: 6 November 2018

Revised: 2 July 2019 - Accepted: 15 July 2019 - Published: 3 September 2019

\begin{abstract}
A reconstruction of hydroclimate with an annual resolution covering millennia for a geographically limited region in continental Europe significantly improves our knowledge of past climate dynamics. With the use of an extensive collection of oak ring-width series (Quercus robur and Quercus petraea) from living trees, historic timbers and subfossil alluvial wood deposits from the Main River region in southern Germany, a regional, 2000-year long, seasonally resolved hydroclimate reconstruction for the Main region has been developed. Climate-growth response analysis has been performed with daily climate records from AD 1900 onwards. To test the stability of the developed transfer function, a bootstrapped transfer function stability test (BTFS) as well as a classical calibration/verification approach have been implemented to study climate-growth model performance. Living oak trees from the Main River region show a significant sensitivity to the precipitation sum from 26 February to 6 July (spring to midsummer) during the full ( $r=0.49, p<0.01$, $N=116)$ and split $(r=0.58, p<0.01, N=58)$ calibration periods. BTFS confirmed the stability of the developed transfer function. The developed precipitation reconstruction reveals high variability on a high- to mid-frequency scale during the past two millennia. Very dry spring to midsummer seasons lasting multiple years appeared in the decades AD 500/510s, 940s, 1170s, 1390s and 1160s. At the end of the AD 330s, a persistent multi-year drought with drastically reduced rainfall (with regard to 1901-2000) could be identi-
\end{abstract}

fied, which was the driest decade over the past 2000 years in this region. In the AD 550s, 1050s, 1310s and 1480s, multi-year periods with high rainfall hit the Main region. In spring to midsummer of $\mathrm{AD} 338$, precipitation was reduced by $\sim 38 \%$ and in AD 357 it increased by $\sim 39 \%$. The presented hydroclimate reconstruction and its comparison to other records reveal interesting insights into the hydroclimate dynamics of the geographically limited area over the Common Era, in addition to revealing noticeable temporal differences.

\section{Introduction}

The observed change in climate in recent decades has already impacted natural and human systems (Stocker et al., 2013). To predict future impacts on the Earth system, it is necessary to investigate past climate dynamics, which requires various climate proxies that have preserved past physical characteristics. Tree rings are widely used as a suitable proxy to reconstruct past climate variability and to provide information on climate fluctuations on a sub-annual basis. Changes in air temperature have been intensively investigated with temperature-sensitive tree-ring chronologies (here, we refer to Wilson et al., 2016; Anchukaitis et al., 2017 and references therein) on a regional to global scale. A comparable number of studies have also investigated long-term (century to millennia) hydroclimate variability, rainfall and drought 
intensity (e.g., Hughes and Brown, 1992; Esper et al., 2007; Cook et al., 2004, 2007, 2015; Stockton and Meko, 1975; Ljungqvist et al., 2016; Prokop et al., 2016; Cooper et al., 2013; Wilson et al., 2005, 2013; Levanič et al., 2013; RuizLabourdette et al., 2014; Seftigen et al., 2017; Helama et al., 2009; Kress et al., 2014). For continental Europe, only a small number of tree-ring hydroclimate reconstructions exist which cover the entire Common Era, and very few studies address the challenge of investigation hydroclimate fluctuations before Common Era (Land et al., 2015; Büntgen et al., 2011; Pechtl and Land, 2019; Schönbein et al., 2015).

The historic instrumental data sets $(\sim 150$ years $)$ are too short to considerably reduce the uncertainty in hydroclimate projections (Ljungqvist et al., 2016). Thus, reconstructions of past hydroclimate variability from tree rings and from a distinct geographical region over substantial parts of the Holocene would allow us to study the natural range of hydroclimatic dynamics on annual to decadal timescales. This would provide a baseline for climate model simulations and improve the verification of model output for predicting future droughts and pluvials.

In this study, a set of total ring-width series from the Main region in southern Germany was used to achieve a robust reconstruction of spring to midsummer precipitation variability. As hydroclimate is generally very localized, limiting the geographic extent of our study to the Main region allows us to create a model that can be used to infer rainfall variability over two millennia. An innovative bootstrapped transfer function stability test (Buras et al., 2017) was used to assess the stability of the applied climate-growth model and the representativeness of the presented reconstruction. We have chosen this specific region since there might be a high potential to develop a hydroclimate record covering the Early, Mid- and parts of the Late Holocene. The connectivity to other existing hydroclimate reconstructions is shown and we critically discuss (a) the feasibility of developing a hydroclimate reconstruction spanning over substantial parts of the Holocene, (b) the potential to obtain information on the frequency and intensity of severe droughts/pluvials lasting over seasons or even decades and (c) the independence of our treering data set compared to other reconstructions from central Europe.

\section{Materials and methods}

\subsection{Tree-ring data}

The Main region (hereafter referred to as MR) is located in Germany and gets its name from the Main River. The Main River originates in the Fichtel Mountains (northeast Bavaria, Germany) and after approximately $500 \mathrm{~km}$ empties into the Rhine River. The Main River is the fourth largest tributary of the Rhine and runs from east to west, which is rare for central Europe. From the MR, total-ring-width (TRW) series were used to construct a composite oak TRW chronology covering

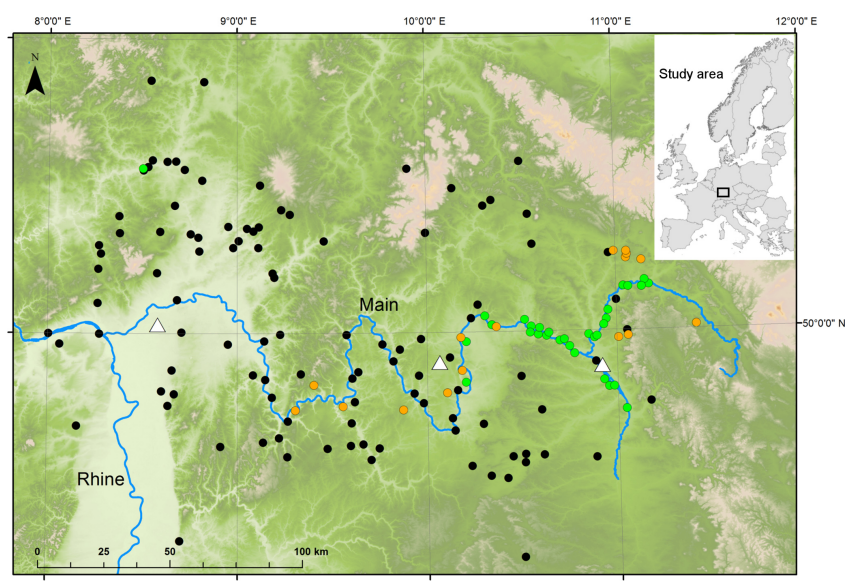

Figure 1. Study area. Locations of the tree-ring sites and meteorological stations in the Main region. The study area is located between $49.3-50.8^{\circ} \mathrm{N}$ and $8.2-12.2^{\circ} \mathrm{E}$. Sites of living trees (orange dots), localities of historical samples from construction wood (black dots) and gravel pits of alluvial deposit subfossil oaks (green dots) are shown. The three meteorological stations (white triangles) are located in the eastern, middle and western parts of the study area.

the period from $\mathrm{AD} 1$ to 2015 . To achieve this, an extensive set of 1405 tree-ring series from this distinct geographical region is available. Such data are generally collected and stored in commercial and university dendro labs all over the world and used to develop robust TRW chronologies with sufficient replication. At the University of Hohenheim, for example, a tree-ring archive of ancient pine (Preboreal pine chronology, PPC) and oak samples (Holocene oak chronology, HOC) spanning the entire Holocene $(\sim 12500$ years; Friedrich et al., 2004) exists, which serves as a suitable archive for studies of past climate variability. The HOC consists of oak samples from quaternary deposits, archeological wood findings, construction timbers and living trees primarily sampled from southern Germany. Together, these form a unique, annually resolved archive, providing an excellent opportunity to study paleoclimate (for details about the PPC and HOC, we refer to Friedrich et al., 2004).

The composite TRW chronology contains tree-ring series from living trees, construction timbers (historical) and alluvial deposits (subfossil). TRW series from historical (Büntgen et al., 2010; Cooper et al., 2013; Wilson and Elling, 2004; Wilson et al., 2005) and archaeological/subfossil material (Kreuzwieser et al., 2004; Land et al., 2015; Schönbein et al., 2015; Pechtl and Land, 2019) have already been used successfully in dendroclimatological studies to reconstruct past hydroclimate variability. All TRW series used for this study originated from a well-defined geographical region between $49.3-50.8^{\circ} \mathrm{N}$ and $8.2-12.2^{\circ} \mathrm{E}$ (Fig. 1).

For calibration, living TRW series were used from locations along the middle and upper Main valley. The specific growth sites of construction timbers used in historical buildings are unknown, but provenance is assumed to be of local 
origin. The historical TRW samples are spread over the entire MR and were obtained from the tree-ring laboratory of the University of Hohenheim and the Hofmann tree-ring laboratory. The TRW series from subfossil oak trunks were derived from quaternary deposits of the upper Main River and the lower Regnitz River.

The entire data set of the original TRW series used for this study is available for public access (see Küppers et al., 2018).

\subsection{Daily meteorological precipitation records}

Daily precipitation sum (DPS) records from three long-term meteorological stations (Fig. 1) were used to assess the hydroclimate response of the TRW chronology. The meteoro-

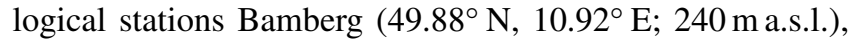
Bergtheim $\left(49.90^{\circ} \mathrm{N}, 10.07^{\circ} \mathrm{E} ; 270 \mathrm{~m}\right.$ a.s.l.) and Frankfurt am Main (a.M.) $\left(50.05^{\circ} \mathrm{N}, 08.60^{\circ} \mathrm{E} ; 112 \mathrm{~m}\right.$ a.s.l.) are located within the MR. The stations were selected due to their long-term DPS records dating back to 1870 (Frankfurt am Main), 1879 (Bamberg) and 1899 (Bergtheim), as well nearly complete status of these records. The data were provided and verified by Royal Netherlands Meteorological Institute (KNMI) Climate Explorer (http://climexp.knmi.nl, last access: 8 June 2017, Klein Tank et al., 2002) and from the Deutscher Wetterdienst (DWD). The DPS record from the Bamberg station did not contain any missing data during the entire period, whereas the DPS records of the Frankfurt am Main and Bergtheim stations had a gap between March and August 1945.

Precipitation sums of each day from all three stations from AD 1900 to 2015 were averaged to obtain a single DPS record representative of the MR. Between March and August 1945, only the Bamberg DPS record was used. This MR DPS was used for climate-growth analysis.

During AD 1901-2000, the mean precipitation sum between 26 February and 6 July (spring to midsummer) was calculated, serving as a reference period. This interval was chosen based on the results of the climate-growth analysis result during calibration.

\subsection{Tree-ring series and chronology construction}

For this study, precisely dated TRW series from oaks were assembled to construct a two millennia composite chronology (AD 1-2015) representing the seasonal radial growth variability within the MR.

The individual TRW series were primarily obtained from the Hohenheim tree-ring archive containing series from subfossil (Quercus sp.), historical (Q. sp.) and living (Q. robur, $Q$. petraea) trees, as well as from the Hofmann tree-ring laboratory (historical series, $Q$. sp.) to establish a wellreplicated TRW chronology. Figure 2 shows the growth period, the mean segment length (MSL) as well as the running inter-series correlation (RBAR) and the expressed population signal (EPS) of the TRW data set (Wigley et al., 1984).

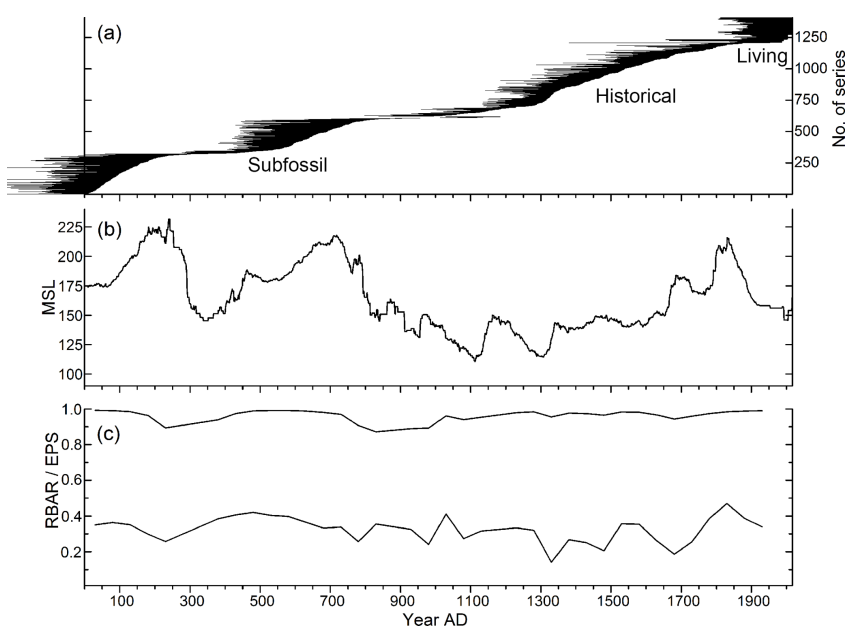

Figure 2. MR oak trees used for the reconstruction. (a) Growth period of living, historical and subfossil tree-ring series, (b) mean segment length (MSL) and (c) inter-series correlation (RBAR) and expressed population signal (EPS) statistics.

For the study, a set of 1405 precisely dated tree-ring series (Küppers et al., 2018) consisting of 618 subfossil, 586 historical and 201 living trees was available (Fig. 2). The subfossil oaks cover the period until AD 1184, and some individual series go back to 321 before the Common Era. Historical tree-ring series range from AD 797 to 1897 and the living series span the period from AD 1380 to 2015. High fluctuations in the replication throughout the study period can be observed, particularly in the subfossil material, indicating a strong river dynamic which led to low/high deposition frequencies. A sufficient overlap between subfossil and historical as well as between historical and living TRW series was ensured.

The raw TRW series were detrended by fitting a fixed 100year cubic smoothing spline (Cook and Peters, 1981) to each individual TRW series. A dimensionless index was obtained by calculating the ratio of the raw and predicted values. The individual detrended TRW series were averaged using the robust bi-weight mean method to develop the standard TRW chronology. Due to fluctuations in the replication, variance stabilization was performed by applying the RBAR-weighted method (Frank et al., 2007; Briffa and Jones, 1990). The above-mentioned standardization procedure was conducted using the ARSTAN software (Cook and Krusic, 2005).

EPS and RBAR are key statistics in dendroclimatology for assessing the representativeness of a TRW chronology. EPS and RBAR statistics were calculated as a quality criterion of the coherence of the TRW chronology. Running EPS and RBAR were calculated during 100 -year periods with a 50year overlap. An EPS value of $>0.85$ was defined as acceptable for a noise-free chronology. Even when concerns regarding the misinterpretation of the EPS threshold have recently been raised (Buras, 2017), we will use the above-mentioned 
EPS threshold to ensure that our study is comparable to others.

\subsection{Calibration, verification and reconstruction of hydroclimate variability}

Tree-ring climate response was assessed using (a) a classical split-period calibration/verification (AD 1900-1957/19582015) and (b) a full period calibration approach (AD 19002015). The correlation coefficient $(r)$ was calculated for calibration and the coefficient of efficiency (CE) for verification (Cook et al., 1994) to assess the reconstruction quality. A $\mathrm{CE}$ greater than zero was assumed to indicate a robust reconstruction.

To assess the temporal stability of the relationship between ring widths and DPS, we applied the bootstrapped transfer function stability test (BTFS; Buras et al., 2017). BTFS bootstraps model parameter ratios between calibration and verification periods of equal length (here, 58 years) for intercept, slope and explained variance over 1000 iterations and tests whether the obtained sample differs significantly from one which would indicate instability of the given parameter. Thus, $p$ values below 0.05 indicate unstable transfer function parameters.

Calibration was conducted between the TRW chronology of the living oak trees and the DPS record. Correlation analysis was performed using a MATLAB ${ }^{\circledR}$ (MathWorks, 19942008) script (Schönbein, 2011) which aggregated DPS data for each year, altering the length of the data interval (from 31 to $361 \mathrm{~d}$ in steps of $10 \mathrm{~d}$ ) and the start date (between 1 January and 15 December). Statistical significance was attained for $\alpha=5 \%$. For details about the running the script, we refer to Schönbein (2011) and Land et al. (2017).

The developed linear climate-growth model was applied to the composite TRW chronology to reconstruct two millennia of hydroclimate variability for the MR. The statistical metric root mean square error (RMSE) was used to measure the climate model performance.

\subsection{Comparison to other hydroclimate reconstructions and independence of the data set}

The developed reconstruction of the MR hydroclimate was compared to other hydroclimate reconstructions available for this region. Pauling et al. (2006) reconstructed the seasonal (spring, summer) precipitation from natural proxies (treering chronologies, ice cores, corals and a speleothem) for European land areas from AD 1500 to 1900 (hereafter referred to as P06sp, P06su). Cook et al. (2015) (hereafter referred to as $\mathrm{C} 15$ ) released a tree-ring-based reconstruction of summer droughts and pluvials (calibrated to scPDSI) over Europe, and Büntgen et al. (2011) (hereafter referred to as B11) reconstructed April-June precipitation sums over central Europe, the latest two studies covering the past two millennia. The mentioned reconstruction series were obtained from the National Oceanic and Atmospheric Administration (http://www.noaa.gov, last access: 8 June 2017) database (grid $49.75^{\circ} \mathrm{N}, 10.25^{\circ} \mathrm{E}$, center).

The set of original single-TRW series included in the respective reconstructions by the mentioned authors is, to the best of our knowledge, not explicitly stated in their work or accessible. This circumstance made a comparison between the respective records extremely difficult. We were therefore unable to check for full independence between the different data sets, meaning that the data set used here might be not fully independent from others, particularly from Middle Ages to the beginning of the modern era. Nevertheless, for the periods in which subfossil and living TRW series have been used, a full independence of the MR exists until C15, B11 and P06. We assume that the historical TRW series MR data set guarantee an independence of at least $55 \%$ over the reconstruction period from $\mathrm{AD} \sim 1150$ to 1700 . At best, the majority $(>80 \%)$ of the MR historical TRW series have not been used by C15, B11 or P06.

It should be mentioned that this is a suboptimal situation for this study which does not allow us to ensure the necessary independence between the data sets but is unfortunately unavoidable in light of the data availability. However, the MR TRW data set used here gives the unique possibility to study the hydroclimate dynamic in a geographically limited area over two millennia.

To expose the common power and relative phase in timefrequency space between the aforementioned and the MR reconstruction, cross-wavelet transform (XWT) was evaluated and wavelet coherence (WTC) was measured by using a MATLAB ${ }^{\circledR}$ script from Grinsted et al. (2004). The XWT finds regions with high common power and WTC shows where the compared series covary in time-frequency space (even when common power is low). For all calculations, the Morlet wavelet was chosen, providing a good balance between time and frequency localization (Grinsted et al., 2004). Additionally, a 51-year running correlation between the MR reconstruction and P06sp, P06su, C15 and B11 was performed. This relatively short window length allows us to study abrupt temporal changes in the behavior of the aforementioned reconstructions.

\section{Results}

\subsection{TRW composite chronology}

The number of TRW series per year fluctuates over time. The lowest replication can be found around AD 280/AD 850, while the highest is in the first decade AD (Fig. 2a). Mean segment length (MSL) is longer for the subfossil and living TRW series and shorter for the historical series but always exceeds 110 years (Fig. 2b). Thus, the temporal fluctuation in MSL limits the extent to which low-frequency signals can be extracted from the TRW data set, like in many other studies dealing with historical oak tree-ring series (see also, e.g., 
Cooper et al., 2013; Wilson et al., 2013). It is likely that the changes in replication and MSL to some extent do bias the developed reconstruction series, even when EPS is $>0.85$. Thus, the developed TRW composite chronology might be biased in the periods $\mathrm{AD} \sim 300$ and $\sim 800$. EPS is always above the threshold of 0.85 during the entire time span (mean EPS of 0.96). The lowest EPS was observed in the transition period of AD 830, where subfossil and historical TRW series overlap, corresponding with low replication. The RBAR is 0.32 (Fig. 2c), showing low values in the first half of the 14th and at the end of the 17th century where the TRW chronology consists of primarily historical TRW series. The decrease in RBAR may lead to a bias in the reconstruction. This is accompanied by increased construction activity in the Main region at the beginning of the 14th century (see the high cutting activity marked by TRW series with a similar end of their growth period in Fig. 2a). In regards to the unknown growth location, and thus the correct origin of the historical trees, the low RBAR could be an artifact of timber trading from outside the study area. The exact oak species $(Q$. robur, $Q$. petraea) used for the reconstruction is also unclear. At the end of 17th century, a TRW set of very old living oak trees are added to the historical data set and may lower RBAR. In periods where only subfossil and living TRW series were used, RBAR increases and is considerably higher, e.g., prior to AD 500 (subfossil) as well as after AD 1830 (living). Further worth mentioning is that the subfossil TRW series seem to be much more homogenous in regards to their inter-series growth pattern than the historical series. The relatively small region of deposited subfossil trees (Fig. 1) could provide an explanation and may hold a more accurate and local climate signal than the historical TRW subset.

\subsection{Climate-growth model and hydroclimate reconstruction}

Figure 3 illustrates the calibration and verification process implemented for the development of the model that was used for further hydroclimate reconstruction.

The TRW chronology reveals a significant relationship $(p<0.01)$ to DPS from 26 February to 6 July (spring to midsummer season) during the full $(r=0.49)$ and split $(r=$ $0.58)$ calibration period. For sensitivity test results of the TRW chronology with total precipitation sum for "classical" monthly resolved seasons, see Table A1 in the Appendix. A $\mathrm{CE}$ of 0.23 accounts for a robust reconstruction. This indicates that the developed climate-growth model is suitable for reconstructing regional hydroclimate variability.

Nevertheless, as can be seen from Fig. 3, the TRW chronology does not track extremely low (e.g., 1903, 1976, 1991, 1993, 2003, 2015) or high (e.g., 1965, 2007) precipitation rates adequately. Thus, the model underestimates the true sum of precipitation in the spring to midsummer season. Similar results were published by other authors (Cooper et al., 2013; Wilson et al., 2013). Based on the work of McCar-

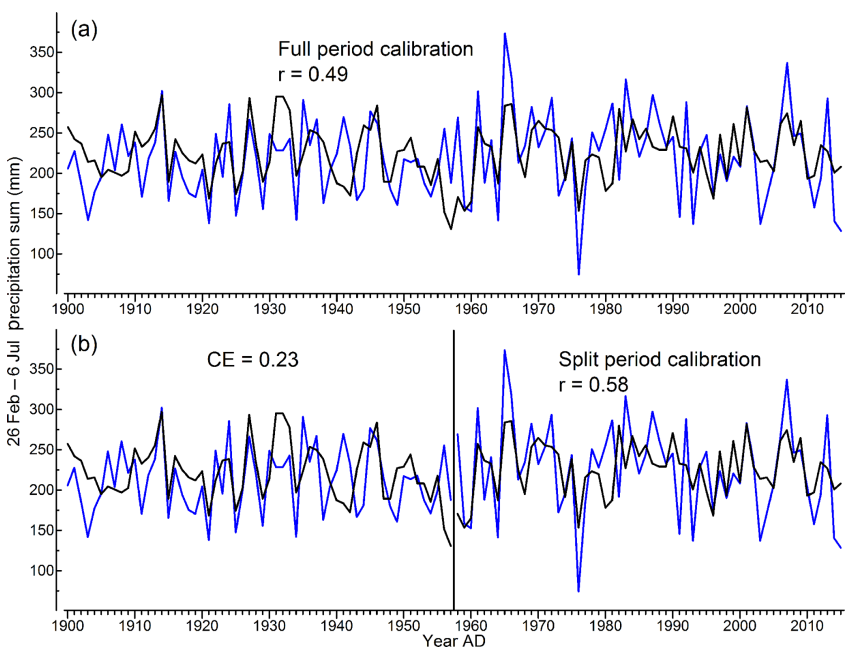

Figure 3. Calibration and verification of the MR oak climateresponse analysis. (a) Full (AD 1900-2015) and (b) split (AD 1958-2015) period calibration. The model was verified during AD 1900-1957. Actual precipitation sums from 26 February to 6 July (blue) and reconstruction (black) are shown.

roll et al. (2015), we simply defined a $10 \%$ threshold of years in which the precipitation sum was low/high during the full calibration period (116 years, $10 \%$ equivalent to 11.6 years each) as extremes. After ranking the precipitation data, we checked how many years of the TRW data capture these extremes. Only 3 years lie beyond the lowest (statistically not significant) but 4 years beyond the highest threshold (statistically significant, $p<0.05$ ). Even though a close statistical relationship between DPS and TRW is evident, there is spurious correlation regarding extreme values.

The applied BTFS indicated stability of transfer function parameters (slope, intercept, $r^{2}$ ) over time ( $p \geq 0.25$ with regard to the null hypothesis of perfectly stable model parameters). A highly significant sign test $(p<0.001)$ revealed true collinearity between TRW and DPS over the calibration period. Model residuals were normally distributed and did not express significant autocorrelations. A moving window correlation between TRW and DPS revealed significant temporal correlations over the calibration; however, these varied between $0.33(p<0.05)$ and $0.60(p<0.001)$.

Both classic calibration/verification as well as BTFS confirm the sensitivity of TRW to 26 February-6 July precipitation totals.

The developed climate-growth model was applied to the composite chronology to reconstruct spring to midsummer (26 February-6 July) precipitation variability for the MR from AD 2015 back to AD 1. The seasonally resolved reconstruction series over two millennia is shown in Fig. 4. The reconstruction maintains high seasonal- as well as decadalscale fluctuations.

The developed reconstruction shows high variability on an annual to decadal timescale with repeated phases of below- 


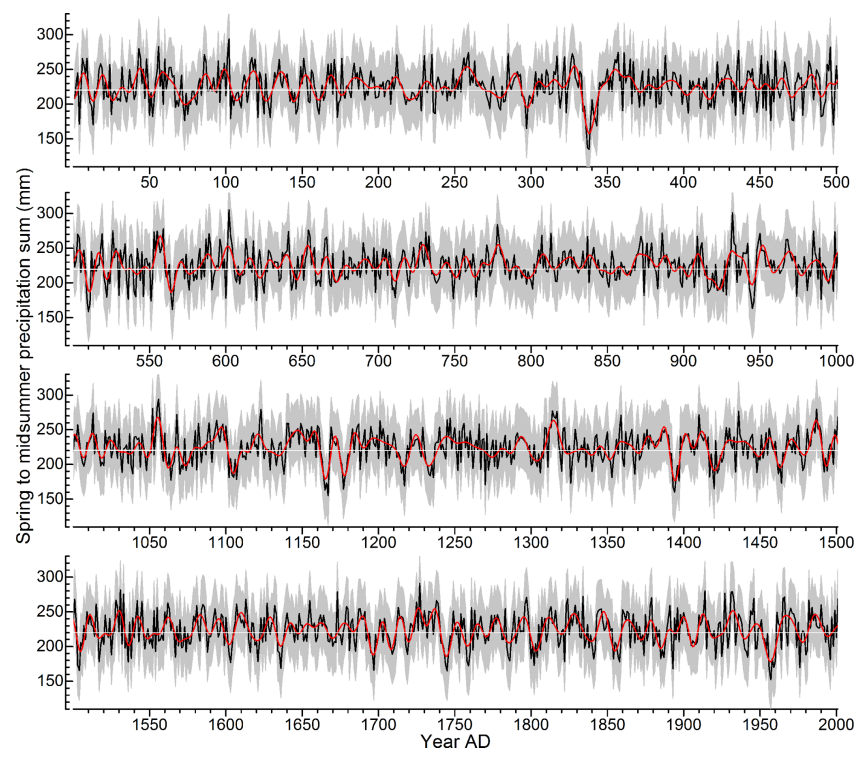

Figure 4. Reconstruction of spring to midsummer season precipitation variability for the MR. Reconstruction of precipitation sum from 26 February to 6 July (black) and 10-year low-pass-filtered reconstruction (red) during AD 1-2000. RMSE (light grey shaded); mean precipitation sum during the AD 1901-2000 reference period (thin white line).

/above-average rainfall. According to our findings, 9 years of less than $25 \%$ of mean precipitation sum (with regard to AD 1901-2000) could be detected (Table 1). The years AD 338 and 337 are marked by severe low pluvials in the MR. In the decade from AD 334 to 344, the MR was exposed to a conspicuous drought far below rainfall average, and thus it can be described as an extraordinarily dry period. In the 12th century (around AD 1165 and 1177) and in the last decade of the 14th century (around AD 1395), three additional periods of below average rainfall occurred. Heavy single-season rainfall exceeding the mean precipitation sum by a minimum of $25 \%$ (with regard to AD 1901-2000) appeared in 26 individual years during the past two millennia (Table 1). The years AD 357 and 985 appear as the wettest seasons with high deviations from the reference period. Periods of unusually high rainfall lasting 5 years or longer appear in the mid-6th, mid-11th and at the beginning of the 14th century. The period from AD 1125 to 1138 is characterized by consistently high pluvials exceeding the average seasonal precipitation sum for almost one and a half decades. A detailed list of dry and wet decades is provided in Table A2.

It can be summarized that the Main region suffered from severe long-lasting droughts and pluvials over the past two millennia, especially during the mid-4th century.
Table 1. List of years with reconstructed far below-/above-average rainfall (26 February-6 July) depicted as deviation (\%) from the AD 1901-2000 reference period.

\begin{tabular}{|c|c|c|c|}
\hline $\begin{array}{l}\text { Year } \\
\mathrm{AD}\end{array}$ & $\begin{array}{l}\text { Low } \\
\text { rainfall }\end{array}$ & $\begin{array}{c}\text { Year } \\
\mathrm{AD}\end{array}$ & $\begin{array}{r}\text { High } \\
\text { rainfall }\end{array}$ \\
\hline 338 & -38 & 357 & 39 \\
\hline 337 & -37 & 985 & 37 \\
\hline 1167 & -29 & 526 & 34 \\
\hline 510 & -28 & 1533 & 34 \\
\hline 1394 & -27 & 654 & 32 \\
\hline 565 & -26 & 1317 & 29 \\
\hline 945 & -26 & 1436 & 29 \\
\hline 1165 & -26 & 460 & 29 \\
\hline \multirow[t]{18}{*}{1177} & -25 & 1314 & 28 \\
\hline & & 436 & 28 \\
\hline & & 559 & 28 \\
\hline & & 1673 & 27 \\
\hline & & 1123 & 27 \\
\hline & & 1487 & 27 \\
\hline & & 43 & 27 \\
\hline & & 1052 & 26 \\
\hline & & 1531 & 26 \\
\hline & & 496 & 26 \\
\hline & & 1055 & 26 \\
\hline & & 56 & 26 \\
\hline & & 778 & 26 \\
\hline & & 1727 & 26 \\
\hline & & 102 & 25 \\
\hline & & 1056 & 25 \\
\hline & & 932 & 25 \\
\hline & & 602 & 25 \\
\hline
\end{tabular}

\subsection{Comparison of MR reconstruction to others}

To evaluate the connection between the MR reconstruction and C15, B11 and P06sp/su, a running correlation (Fig. A1 in Appendix) as well as wavelet analyses between MR and C15/B11 were performed (Fig. 5).

The 51-year running correlation accounts for temporal variation between the reconstructions. The correlation between MR and C15/B11 is high from the 12th until the 18th century. Before the 12th and from the 18th century onwards, the agreement declined to sporadic cases. Around AD 300 and 400 as well as during the 9th century, the MR shows only weak connections to C15 and B11. In the mid-19th century, MR and B11 have no statistical relationship. When the MR is compared to P06sp and P06su, a relationship is only evident during short time periods. Especially during the end of the 17 th to the mid-18th century as well as over the 20th century, an agreement to P06sp/su is not detectable. In general, MR and P06sp/su are only spuriously related.

Figure 5 shows the cross-wavelet transform (XWT) and the wavelet coherence (WTC) between MR and B11 and MR and $\mathrm{C} 15$ over two millennia. 

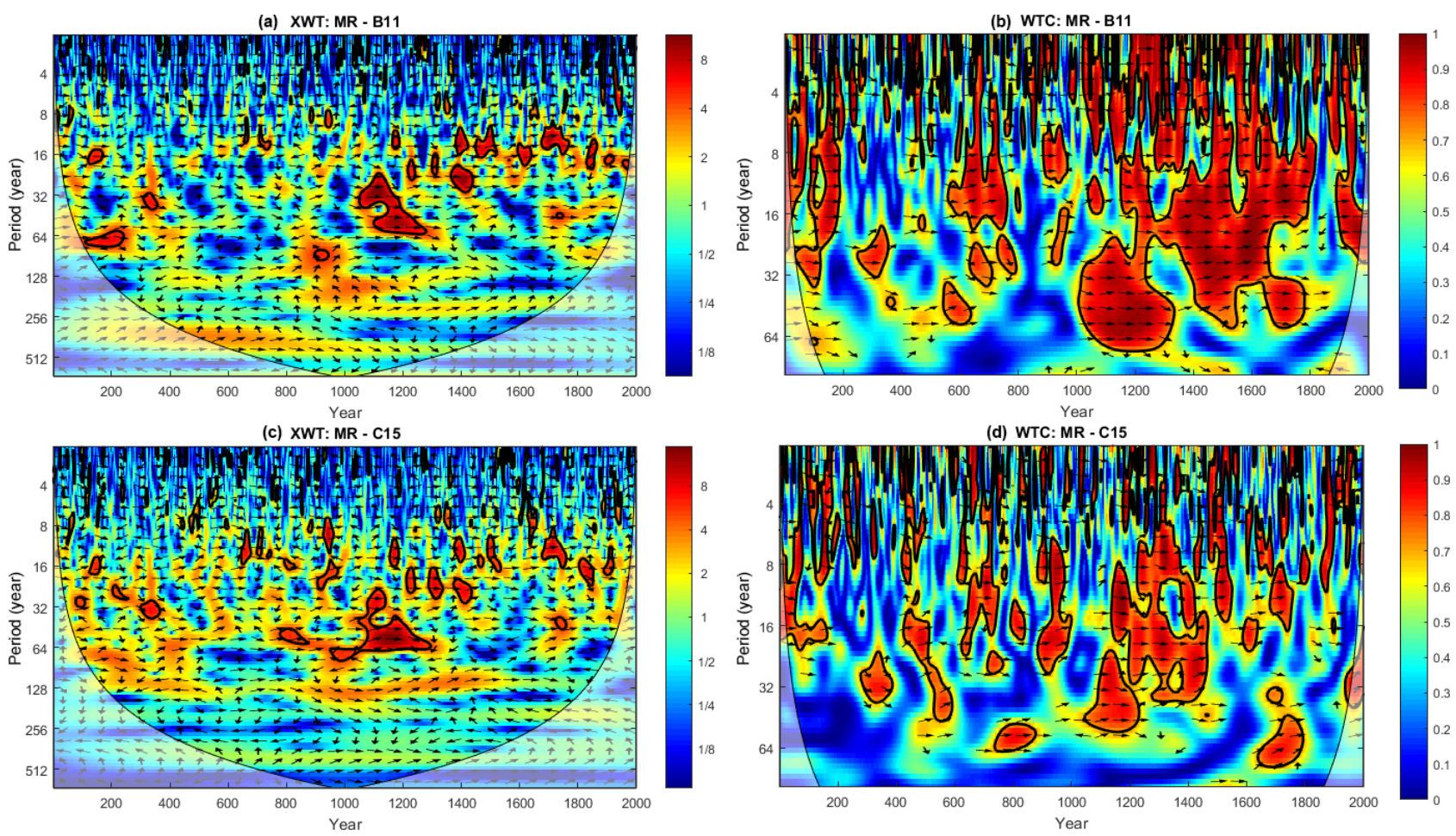

Figure 5. Cross-wavelet transform (XWT, a, c) and squared wavelet coherence (WTC, b, d) between MR-B11 (a, b) and MR-C15 (c, d) from AD 1-2000. A $5 \%$ significance level against red noise is shown as a thick contour. Light shading depicts the cone of influence. Right-pointing arrows show in-phase and left-pointing arrows show anti-phase behavior.

The XWT between MR-B11 shows significant common power in the $\sim 10$ - to 15 -year band from the 12 th century onwards and in the $\sim 20$ - to 60 -year band around the 11th and 12 th centuries. The XWT between MR-C15 depicts similar results. Albeit, the $\sim 23$ - to 65-year band from AD 1000 to 1300 is more pronounced. Looking at the squared coherence spectrum (WTC) between MR-B11 and MR-C15, the close connections appear on the $\sim 4$-year band and are more pronounced on the 10 - to 60 -year band, especially after AD 1000. Nevertheless, there is a distinct difference between pre- and post-AD 1000. Coherence between MR-B11 and MR-C15 is also obvious prior to AD 1000, on short as well as on long terms, but not as high as in the second millennium. The right-pointing arrows in the significant regions (thick contours in the right panels of Fig. 5) indicate that the compared reconstructions clearly swing in phase, holding evidence for close time-frequency connections. The previously mentioned weak connection between MR and C15 in some periods (Fig. A1) becomes more obvious from the WTC. From AD 200 to 400, for example, no significant connection on shorter and even on longer timescales can be found, supporting the results from the running correlation analysis and indicating substantial differences between the different reconstruction series to the regional MR. The weaker, or even non-significant, connections between MR-B11 and MR-C15 in the first millennium AD show that there is a par- ticularly low coherence between the regional hydroclimate reconstruction (MR) and B11/C11 when an independent data set (see Sect. 2.5) is used.

Figure 6 shows the 20-year low-pass-filtered reconstructions from MR, B11 and C15 from AD 1 to 2000 (Fig. 6a) as well as for two subperiods with an annual resolution (Fig. 6b, c).

As shown in the previous section, the reconstruction series contain differences and similarities on year-to-year and midfrequency fluctuations. It is obvious from Fig. 6a that MR, $\mathrm{C} 15$ and B11 hold strong discrepancies regarding their fluctuations until the end of the 7th century (see also Fig. 5). For example, B11 shows a much higher fluctuation on a longer timescale between AD 250 and 700 than C15 and MR. However, during the aforementioned dry decade around AD 338 (Fig. 6b), all three reconstructions independently show similar patterns and document a long-lasting drought. On the other hand, the pronounced long-lasting drought in the 6th century as reconstructed by B11 is not seen in MR or C15. Although C15 and B11 show evidence of a severe wet decade around $\mathrm{AD} 435$, the MR does not confirm this result. On the contrary, the MR shows moderate changes on a midfrequency scale. From the end of the 11th to the mid-18th century, all reconstruction series show highly similar patterns (Figs. 5, 6c; Fig. A1) from year to year and on mid-frequency, with the exception of P06sp/su. They share changes in the 


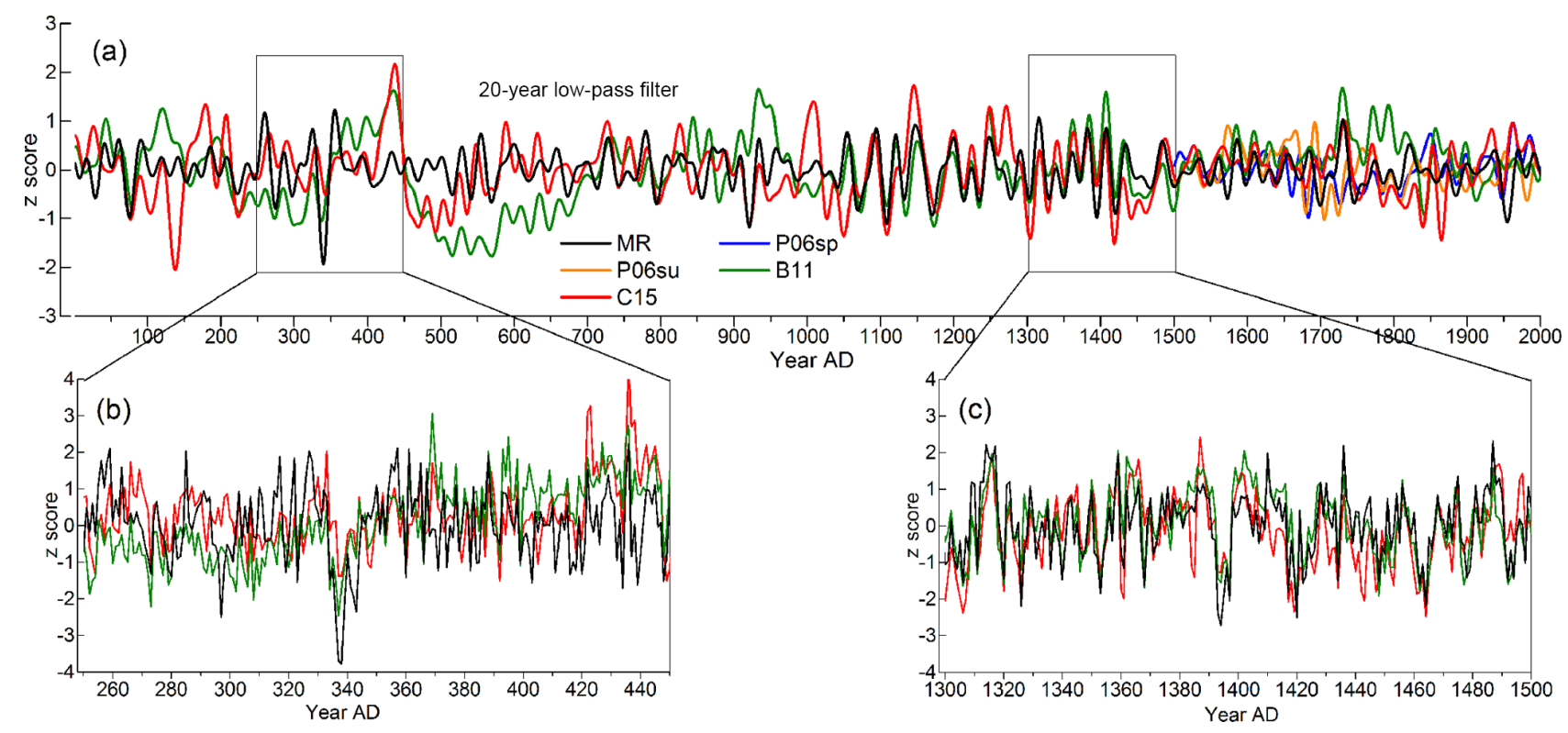

Figure 6. Smoothed hydroclimate reconstructions from AD 1 to 2000: (a) 20-year low-pass-filtered reconstructions, (b) annual fluctuations from $\mathrm{AD} 250$ to 450 and (c) those from $\mathrm{AD} 1300$ to 1500 .

amplitude synchronously even in very wet and severely dry years/periods. In particular, from AD 1800 onwards, when full independence of the MR data set is guaranteed, notable differences occur. Running correlation analyses also account for substantial differences between the MR and the other reconstructions over the last two centuries (see also Fig. A1).

\section{Discussion}

\subsection{Climate sensitivity of the MR TRW chronology and stability of transfer function}

The oak TRW chronology from the Main region (MR) in southern Germany reveals a significant $(p<0.01)$ sensitivity to the precipitation sum from 26 February to 6 July (spring to midsummer season). During calibration and verification, it became clear that TRW does not cover the full range of precipitation variability, resulting in a poor correlation between TRW and extremes. Low and high seasonal precipitation sums are not accurately reflected in the applied climategrowth model, which is also mentioned by, e.g., Cooper et al. (2013) and Wilson et al. (2013). Land et al. (2017) pointed out that oak tree-ring series are not sensitive to short, heavy rainfall events during the growing season, which may provide a further explanation for this fact. Another reason could be a loss of photosynthetically active leaf area caused by fungal infestations (e.g., mildew) during such phases of high precipitation. We further note that in the MR, a massive insect attack took place between AD 1954 and 1958 (Steger, 1959, 1960), which reduced growth considerably and certainly influenced the climate-growth model performance. The complexity of oak growth over the course of the 20th century is also well established. Friedrichs et al. (2008) showed that oak growth can increase when a combination of warm and dry conditions occur. This leads to the assumption that the control of oak growth remains complex, at least during isolated periods. Altogether, the applied climate-growth model considerably underestimates the total seasonal precipitation sum, which leads to a loss of explained variance.

The precipitation sensitivity of the MR oaks does, however, agree with findings from other studies conducted with oak tree-ring series in Europe. Büntgen et al. (2011) reported a sensitivity of the seasonal precipitation sum from April to June (central Europe), while Friedrichs et al. (2008) (central-west Germany) and Čufar et al. (2008) (southeast Slovenia) showed this for the June rainfall sum. Cooper et al. (2013) (East Anglian), Wilson et al. (2013) (south-central England) and Karanitsch-Ackerl et al. (2017) (northeast Austria) found a close relationship to March-July precipitation sum and Land (2014), Land et al. $(2015,2017)$ and Schönbein et al. (2015) (Franconia, Germany) to spring-summer precipitation.

European oak TRW chronologies show an explicit connection to hydroclimate during the growing season, in particular from spring until midsummer.

\subsection{Main region hydroclimate dynamic}

The developed climate-growth model leaves a high level of unexplained variance, which is most apparent in seasons with far below-/above-average rainfall totals. This leads to an inevitable underestimation of past climate variability and is also reported from other authors (Cooper et al., 2013; Esper et al., 2005; von Storch et al., 2004; Wilson et al., 2013; 
Bürger et al., 2006; Christiansen and Ljungqvist, 2017). Thus, we can assume that in the MR, the year-to-year dynamic might be much more variable than suggested by the tree rings due to the tree rings' inability to capture years with extreme low/high precipitation. This would mean that during the past two millennia, very low/high pluvials are much more pronounced, and thus the hydroclimate dynamic is stronger than suggested by the presented reconstruction. While the oak tree-ring series used here respond very well to spring-summer rainfall during the calibration/verification period, it is not unlikely that, to some extent, warmer/colder phases during the past two millennia (e.g., the Medieval Climate Anomaly or the Little Ice Age) affect the presented reconstruction. It has been shown by Friedrichs et al. (2008) that oak trees from central-west Germany (which is close to our study region) lose their precipitation sensitivity in the anomalously warm 1940s decade. This decreased response to hydroclimatic conditions in central Germany has been confirmed by Büntgen et al. (2010), whose study revealed that oak TRW sensitivity is greatly reduced to scPDSI in the mid-20th century. A well-established decrease in precipitation sensitivity during the 1940s is also observed in our study (data not shown). With this in mind, it is possible that during extraordinary warm (Medieval Climate Anomaly) or extraordinary cold (Little Ice Age) (Mann et al., 2009) periods, TRW reconstructions may show a certain level of bias. However, it remains unclear to what extent the reconstruction here presented is biased.

On the other hand, a severely reduced growth of oak trees does not necessarily mean a "true" dry season but may instead be due to a combination of moderate rainfall, a warm spring season and/or an insect attack. Oak trees are prone to insect attacks, especially under natural forest dynamic processes within a small region. Capturing non-climate-driven tree-ring fluctuations, e.g., caused by insects, would therefore necessitate an investigation of wood anatomy which, due to the high number of wood samples, would be labor intensive and cost prohibitive. An attempt of such can be found in Land et al. (2015) and Schönbein et al. (2015). Nevertheless, single seasons with pronounced below-average (e.g., AD 338)/above-average (e.g., AD 357) average rainfall totals as well as very dry several-year periods (e.g., around AD 1395) appeared in the MR. Interestingly, Spurk et al. (2002) investigated the depositional frequency of subfossil oaks in the MR, which includes the tree samples used here, and linked them to climatically induced fluctuations. They found a sudden onset of germination at AD 400 in the MR, indicating humid conditions. From AD 400 onwards, our reconstruction gives no evidence for a continuous longlasting period with above-average rainfall but shows distinct high year-to-year fluctuations between AD 420 and 550. Despite that, changes on a low-frequency scale over centuries to millennia are masked by the standardization procedure.

Nevertheless, due to the changes in the mean segment length and the highly variable sample replication, the stan- dardization procedure applied here (100-year spline) is suitable for preserving high- to mid-frequency fluctuations, while the low-frequency variance from the TRW data set is removed. Thus, no inferences can be made for centenniallong precipitation fluctuations for the study region. When comparing the MR hydroclimate reconstruction to B11 and C15 (both capturing the low-frequency domain, e.g., by using RCS detrending), some differences appear on the lowfrequency timescale. These are especially apparent in the first millennium $\mathrm{AD}$, where trees from alluvial deposits are available for reconstruction purposes, and is more pronounced between MR-B11 than between MR-C15.

As mentioned by Spurk et al. (2002), human influence could have had a severe impact on forest structure and forest dynamic since the third millennium before Common Era and may have therefore impacted the dynamic of tree growth, perhaps leading to a bias in the established reconstruction. Therefore, investigating epochs where human impact is low, or at best did not occur, is crucial to get a clear picture of pre-human time and its climate dynamic. However, it should be mentioned that humans already settled in the MR over 7000 years ago (Bickle and Whittle, 2013) and certainly influenced their environment accordingly. Much more effort must be made in the future to fully understand the hydroclimate dynamic on a small scale (e.g., in the Main region) during the entire Holocene. Even when the tree rings used represent a highly resolved natural archive, combining different scientific fields, e.g., as recently done by Pechtl and Land (2019), is very necessary to capture potential human effects on former forests. Another factor plays a crucial role: for southern Germany (and for large parts of central Europe), oak is the only species from which TRW series are available from the present back to the Early/Mid-Holocene. It is therefore of tremendous interest for paleoclimate research to interpret the growth fluctuations more precisely and to enhance climate-growth model performance.

\subsection{Comparison and independence of MR to other hydroclimate reconstructions}

The reconstruction of spring to midsummer precipitation variability for the MR developed here shows high connectivity to C15 (Cook et al., 2015) and B11 (Büntgen et al., 2011) for substantial parts of the past two millennia, which is apparent on different time-frequency domains as well as from continuous in-phase fluctuations. Nevertheless, the results of running correlations and wavelet coherence analyses clearly speak for notable differences during some periods. These differences are particularly obvious around AD 300-400, 750 850 and $1820-1870$, accounting for intervals where the MR TRW data set is fully independent from others. The differences can primarily be observed on a mid-frequency scale but are also seen in year-to-year fluctuations. We assume that one reason for this could lie in the differing standardization procedures utilized in chronology construction, while the use 
of mixed TRW series from various provenance and from different sources (archeological findings) could also play a considerable role (for more details, we refer to the mentioned studies). This underlines the significance of this study, as it presents a hydroclimate reconstruction for a small geographical region in southern Germany, in addition to providing a new time series that can contribute to investigations about past European hydroclimate variability.

The high connectivity between MR-C15 and MR-B11 over $\sim 700$ years (end of 11 th to mid-18th century) is outstanding and supports the assumption that duplicates within the TRW data are used in the different studies. The exact level of dependency between the different data sets cannot be stated here and remains undetermined. Thus, we assume that during this period our TRW data set might be not as independent as initially considered, which once again highlights the importance of data transparency.

Nevertheless, the MR hydroclimate reconstruction accounts for an on-site variability.

Developing a hydroclimate reconstruction for central Europe reaching back to the Early/Mid-Holocene requires a large data set with a sufficient number of TRW series. This goal could be achieved with the use of TRW series from the Hohenheim Holocene oak chronology (HOC) (Friedrich et al., 2004), assuming that these subfossil oaks reflect the representative central European hydroclimate. The results of our study support the assumption that the TRW series from the Main region, consisting of a well-replicated TRW data set (for more details, see Friedrich et al., 2004; Leuschner et al., 2002; Spurk et al., 2002), have the potential to reflect the rainfall variability of central Europe, at least for southern Germany, as well as regional hydro-regime aspects. Nevertheless, a 10-millennia hydroclimate reconstruction would require the inclusion of TRW data from other river systems (e.g., upper Danube, upper Rhine) due to changes in the deposition frequency of oak trunks and the resultant variance in replication (Spurk et al., 2002; Friedrich et al., 2004). Such temporal changes of distribution are known from tree-ring archives of Ireland, northern Germany and the Netherlands (Leuschner et al., 2002; Spurk et al., 2002) as well. Combining such TRW data sets lasting for millennia from different regions or countries across Europe is crucial for the development of a well-replicated reconstruction representing the overall European seasonal rainfall variability during substantial parts of the Holocene. Additional regional investigations of hydroclimate variability that cover multiple millennia must also be conducted.

\section{Conclusions}

We conclude that oak TRW in the Main region is suitable to reconstruct past hydroclimate conditions with an annual resolution during the past two millennia as well as for the investigation of rainfall intensity on a high- to mid-frequency scale. Moreover, the developed hydroclimate reconstruction is, to the best of our knowledge, the only record covering two millennia with seasonal resolution for a geographically limited area in central Europe. When the presented hydroclimate reconstruction is compared to others, it becomes apparent that significant differences on an annual to decadal scale appear under the assumption of a fully independent TRW data set. This raises the question about the potential to upscale or to transfer these results to a wider geographical extent. Finally, we hypothesize that a tree-ring hydroclimate reconstruction over the entire Holocene is feasible using a large TRW data set from different river systems in southern Germany, which also may hold the unique potential to reveal insights into central European hydroclimate fluctuations on a seasonal scale.

Data availability. The entire data set of the original TRW series can be accessed via https://doi.org/10.5281/zenodo.1453330 (Küppers et al., 2018). 


\section{Appendix A}

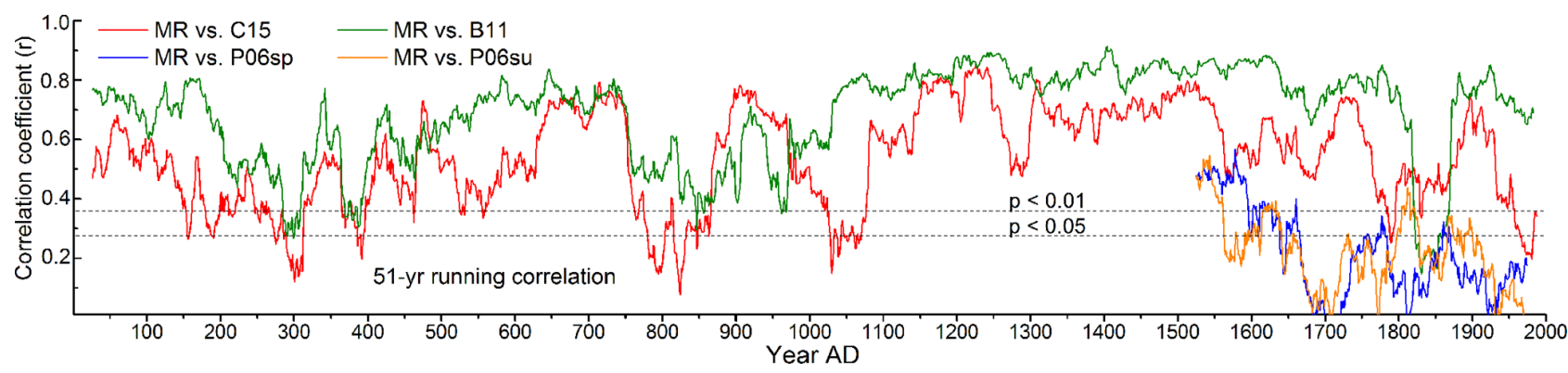

Figure A1. Comparison of MR precipitation reconstruction to other reconstructions of rainfall variability. Statistical comparison (51year running correlation) between the MR reconstruction and C15 (Cook et al., 2015), B11 (Büntgen et al., 2011) and P06sp/su (Pauling et al., 2006).

Table A1. TRW response to total precipitation sum in different calibration windows (seasons) from AD 1900 to $2015(N=116) . r$ is the correlation coefficient, $p$ is the probability value, and n.s. is "not significant".

\begin{tabular}{lrr}
\hline Calibration window & $r$ & $p<$ \\
\hline 26 Feb-6 Jul (this study) & 0.49 & 0.01 \\
Apr-Jun & 0.47 & 0.01 \\
Jun-Aug & 0.16 & n.s. \\
Mar-Aug & 0.29 & 0.01 \\
Mar-Jul & 0.37 & 0.01 \\
Mar-May & 0.31 & 0.01 \\
\hline
\end{tabular}

Table A2. Reconstructed dry and wet decades from AD 1 to 1900 Dry/wet decade is a 10-year average of reconstructed precipitation $<190 />250 \mathrm{~mm}$ (with regard to AD 1901-2000 equivalent to $220 \mathrm{~mm})$.

\begin{tabular}{|c|c|}
\hline $\begin{array}{l}\text { Dry } \\
\text { decades }\end{array}$ & $\begin{array}{r}\text { Wet } \\
\text { decades }\end{array}$ \\
\hline & $40 \mathrm{~s}$ \\
\hline & $90 \mathrm{~s}$ \\
\hline & $250 \mathrm{~s}$ \\
\hline & $320 \mathrm{~s}$ \\
\hline \multicolumn{2}{|l|}{$330 \mathrm{~s}$} \\
\hline & $350 \mathrm{~s}$ \\
\hline $510 \mathrm{~s}$ & $550 \mathrm{~s}$ \\
\hline \multicolumn{2}{|l|}{$560 \mathrm{~s}$} \\
\hline & $600 \mathrm{~s}$ \\
\hline & $650 \mathrm{~s}$ \\
\hline & $720 \mathrm{~s}$ \\
\hline & $770 \mathrm{~s}$ \\
\hline & $950 \mathrm{~s}$ \\
\hline & $1050 \mathrm{~s}$ \\
\hline & $1090 \mathrm{~s}$ \\
\hline \multirow{3}{*}{\multicolumn{2}{|c|}{$\begin{array}{l}1100 \mathrm{~s} \\
1160 \mathrm{~s} \\
1170 \mathrm{~s}\end{array}$}} \\
\hline & \\
\hline & \\
\hline & $1310 \mathrm{~s}$ \\
\hline & $1380 \mathrm{~s}$ \\
\hline \multicolumn{2}{|l|}{$1390 \mathrm{~s}$} \\
\hline & $1480 \mathrm{~s}$ \\
\hline & $1530 \mathrm{~s}$ \\
\hline \multicolumn{2}{|l|}{$1690 \mathrm{~s}$} \\
\hline & $1720 \mathrm{~s}$ \\
\hline & $1730 \mathrm{~s}$ \\
\hline $1740 \mathrm{~s}$ & $1840 \mathrm{~s}$ \\
\hline
\end{tabular}


Author contributions. AL compiled the dendroclimatic analyses and the hydroclimate reconstruction, and wrote the manuscript. SR, $\mathrm{DR}, \mathrm{ME}$ and $\mathrm{SH}$ processed the TRW measurements and wrote parts of the manuscript. $\mathrm{CZ}$ and $\mathrm{AB}$ performed the bootstrapped stability test and wrote parts of the manuscript. JH particularly provided historical TRW data. All authors read and approved the final manuscript.

Competing interests. The authors declare that they have no conflict of interest.

Acknowledgements. We are grateful to Bernd Becker, Marco Spurk and Michael Friedrich for continuous sampling of trees from alluvial deposits and construction timbers. We especially thank Bernd Becker, as he set up the Hohenheim Holocene oak chronology (HOC) with great personal effort. We acknowledge Manfred Küppers for critical notes on the study and for the provided data set of the HOC. This study greatly benefited from comments of an anonymous reviewer on a previous version of the paper.

Review statement. This paper was edited by Hans Linderholm and reviewed by Fredrik Charpentier Ljungqvist, Johannes Edvardsson, and two anonymous referees.

\section{References}

Anchukaitis, K. J., Wilson, R., Briffa, K. R., Büntgen, U., Cook, E. R., D’Arrigo, R., Davi, N., Esper, J., Frank, D., Gunnarson, B. E., Hegerl, G., Helama, S., Klesse, S., Krusic, P. J., Linderholm, H. W., Myglan, V., Osborn, T. J., Zhang, P., Rydval, M., Schneider, L., Schurer, A., Wiles, G., and Zorita, E.: Last millennium Northern Hemisphere summer temperatures from tree rings: Part II, spatially resolved reconstructions, Quaternary Sci. Rev., 163, 1-22, https://doi.org/10.1016/j.quascirev.2017.02.020, 2017.

Bickle, P. and Whittle, A. W. R.: The first farmers of central Europe: Diversity in LBK lifeways, Cardiff Studies in Archaeology, Oxbow Books and the David Brown Book Company, Oakville, CT, 528 pp., 2013.

Briffa, K. R. and Jones, P. D.: Basic chronology statistics and assessment, in: Methods of dendrochronology: applications in the environmental sciences, edited by: Cook, E. R. and Kairiukstis, L. A., Kluwer Academic Publishers, Dordrecht, 137-152, 1990.

Büntgen, U., Trouet, V., Frank, D., Leuschner, H. H., Friedrichs, D., Luterbacher, J., and Esper, J.: Tree-ring indicators of German summer drought over the last millennium, Quaternary Sci. Rev., 29, 1005-1016, https://doi.org/10.1016/j.quascirev.2010.01.003, 2010.

Büntgen, U., Tegel, W., Nicolussi, K., McCormick, M., Frank, D., Trouet, V., Kaplan, J. O., Herzig, F., Heussner, K.-U., Wanner, H., Luterbacher, J., and Esper, J.: 2500 years of European climate variability and human susceptibility, Science, 331, 578582, https://doi.org/10.1126/science.1197175, 2011.

Buras, A.: A comment on the expressed population signal, Dendrochronologia, 44, 130-132, https://doi.org/10.1016/j.dendro.2017.03.005, 2017.
Buras, A., Zang, C., and Menzel, A.: Testing the stability of transfer functions, Dendrochronologia, 42, 56-62, https://doi.org/10.1016/j.dendro.2017.01.005, 2017.

Bürger, G., Fast, I., and Cubasch, U.: Climate reconstruction by regression - 32 variations on a theme, Tellus A, 58, 227-235, 2006.

Christiansen, B. and Ljungqvist, F. C.: Challenges and perspectives for large-scale temperature reconstructions of the past two millennia, Rev. Geophys., 55, 40-96, https://doi.org/10.1002/2016RG000521, 2017.

Cook, E. R. and Krusic, P. J.: Program ARSTAN: A Tree-Ring Standardization Program Based on Detrending and Autoregressive Time Series Modeling, with Interactive Graphics, Tree-Ring Laboratory, Lamont Doherty Earth Observatory of Columbia University Palisades, Palisades, NY, 2005.

Cook, E. R. and Peters, K.: The smoothing spline: A new approach to standardizing forest interior tree-ring width series for dendroclimatic studies, Tree-Ring Bull., 41, 45-53, 1981.

Cook, E. R., Briffa, K. R., and Jones, P. D.: Spatial regression methods in dendroclimatology: A review and comparison of two techniques, Int. J. Climatol., 14, 379-402, 1994.

Cook, E. R., Woodhouse, C. A., Eakin, C. M., Meko, D. M., and Stahle, D. W.: Long-Term Aridity Changes in the Western United States, Science, 306, 1015-1018, https://doi.org/10.1126/science.1102586, 2004.

Cook, E. R., Seager, R., Cane, M. A., and Stahle, D. W.: North American drought: Reconstructions, causes, and consequences, Earth-Sci. Rev., 81, 93-134, https://doi.org/10.1016/j.earscirev.2006.12.002, 2007.

Cook, E. R., Seager, R., Kushnir, Y., Briffa, K. R., Büntgen, U., Frank, D., Krusic, P. J., Tegel, W., van der Schrier, G., AndreuHayles, L., Baillie, M., Baittinger, C., Bleicher, N., Bonde, N., Brown, D., Carrer, M., Cooper, R., Čufar, K., Dittmar, C., Esper, J., Griggs, C., Gunnarson, B., Gunther, B., Gutierrez, E., Haneca, K., Helama, S., Herzig, F., Heussner, K.-U., Hofmann, J., Janda, P., Kontic, R., Kose, N., Kyncl, T., Levanič, T., Linderholm, H., Manning, S., Melvin, T. M., Miles, D., Neuwirth, B., Nicolussi, K., Nola, P., Panayotov, M., Popa, I., Rothe, A., Seftigen, K., Seim, A., Svarva, H., Svoboda, M., Thun, T., Timonen, M., Touchan, R., Trotsiuk, V., Trouet, V., Walder, F., Wazny, T., Wilson, R., and Zang, C.: Old World megadroughts and pluvials during the Common Era, Sci. Adv., 1, 1-9, https://doi.org/10.1126/sciadv.1500561, 2015.

Cooper, R. J., Melvin, T. M., Tyers, I., Wilson, Rob J. S., and Briffa, K. R.: A tree-ring reconstruction of East Anglian (UK) hydroclimate variability over the last millennium, Clim. Dynam., 40, 1019-1039, https://doi.org/10.1007/s00382-012-1328-x, 2013.

Čufar, K., Luis, M. de, Eckstein, D., and Kajfez-Bogataj, L.: Reconstructing dry and wet summers in SE Slovenia from oak tree-ring series, Int. J. Biometeorol., 52, 607-615, https://doi.org/10.1007/s00484-008-0153-8, 2008.

Esper, J., Wilson, R. J. S., Frank, D. C., Moberg, A., Wanner, H., and Luterbacher, J.: Climate: past ranges and future changes, Quaternary Sci. Rev., 24, 2164-2166, https://doi.org/10.1016/j.quascirev.2005.07.001, 2005.

Esper, J., Frank, D., Büntgen, U., Verstege, A., Luterbacher, J., and Xoplaki, E.: Long-term drought severity variations in Morocco, Geophys. Res. Lett., 34, 1-5, 2007.

Frank, D., Esper, J., and Cook, E. R.: Adjustment for proxy number and coherence in a large-scale tem- 
perature reconstruction, Geophys. Res. Lett., 34, 1-5, https://doi.org/10.1029/2007GL030571, 2007.

Friedrich, M., Remmele, S., Kromer, B., Spurk, M., Hofmann, J., Hurni, J. P., Kaiser, K. F., and Küppers, M.: The 12.460year Hohenheim oak and pine tree-ring chronology from Central Europe - a unique annual record for radiocarbon calibration and palaeoenvironment reconstructions, Radiocarbon, 46, 11111122,2004

Friedrichs, D. A., Büntgen, U., Frank, D. C., Esper, J., Neuwirth, B., and Löffler, J.: Complex climate controls on 20th century oak growth in Central-West Germany, Tree Physiol., 29, 39-51, https://doi.org/10.1093/treephys/tpn003, 2008.

Grinsted, A., Moore, J. C., and Jevrejeva, S.: Application of the cross wavelet transform and wavelet coherence to geophysical time series, Nonlin. Processes Geophys., 11, 561-566, https://doi.org/10.5194/npg-11-561-2004, 2004.

Helama, S., Meriläinen, J., and Tuomenvirta, H.: Multicentennial megadrought in northern Europe coincided with a global El Nino-Southern Oscillation drought pattern during the Medieval Climate Anomaly, Geology, 37, 175-178, https://doi.org/10.1130/G25329A.1, 2009.

Hughes, M. and Brown, P.: Drought frequency in central California since 101 B.C. recorded in giant sequoia tree rings, Clim. Dynam., 6, 161-167, https://doi.org/10.1007/BF00193528, 1992.

Karanitsch-Ackerl, S., Holawe, F., Laaha, G., Wimmer, R., and Grabner, M.: Parameter-specific hydroclimatic sensitivity of a low-elevation network of living and historical tree-ring series from north-eastern Austria, Dendrochronologia, 45, 39-51, 2017

Klein Tank, A. M. G., Wijngaard, J. B., Können, G. P., Böhm, R., Demarée, G., Gocheva, A., Mileta, M., Pashiardis, S., Hejkrlik, L., Kern-Hansen, C., Heino, R., Bessemoulin, P., MüllerWestermeier, G., Tzanakou, M., Szalai, S., Pálsdóttir, T., Fitzgerald, D., Rubin, S., Capaldo, M., Maugeri, M., Leitass, A., Bukantis, A., Aberfeld, R., van Engelen, A. F. V., Forland, E., Mietus, M., Coelho, F., Mares, C., Razuvaev, V., Nieplova, E., Cegnar, T., Antonio López, J., Dahlström, B., Moberg, A., Kirchhofer, W., Ceylan, A., Pachaliuk, O., Alexander, L. V., and Petrovic, P.: Daily dataset of 20th-century surface air temperature and precipitation series for the European Climate Assessment, Int. J. Climatol., 22, 1441-1453, https://doi.org/10.1002/joc.773, 2002.

Kress, A., Hangartner, S., Bugmann, H., Büntgen, U., Frank, D. C., Leuenberger, M., Siegwolf, R. T. W., and Saurer, M.: Swiss tree rings reveal warm and wet summers during medieval times, Geophys. Res. Lett., 41, 1732-1737, https://doi.org/10.1002/2013GL059081, 2014.

Kreuzwieser, J., Papadopoulou, E., and Rennenberg, H.: Interaction of flooding with carbon metabolism of forest trees, Plant Biol., 6, 299-306, 2004.

Küppers, M., Remmele, S., Hofmann, J., and Land, A.: Two millennia of Main region (southern Germany) hydroclimate variability [data file], available at: https://doi.org/10.5281/zenodo.1453330, last access: 9 October 2018.

Land, A.: Holzanatomische Veränderungen als Reaktion auf extreme Umweltereignisse in rezenten und subfossilen Eichen und deren Verifizierung im Experiment, PhD-Thesis, Institut für Botanik, University of Hohenheim, Stuttgart-Hohenheim, 187 pp., 2014.
Land, A., Schönbein, J., and Friedrich, M.: Extreme climate events identified by wood-anatomical features for the Main region (Southern Germany) - A case study for 3000-2000 BC, in: 2200 BC - A climatic breakdown as a cause for the collapse of the old world?, edited by: Meller, H., Arz, H. W., Jung, R., and Risch, R., 595-602, 2015.

Land, A., Remmele, S., Schönbein, J., Küppers, M., and Zimmermann, R.: Climate-growth analysis using long-term dailyresolved station records with focus on the effect of heavy precipitation events, Dendrochronologia, 45, 156-164, 2017.

Leuschner, H. H., Sass-Klaassen, U., Jansma, E., Baillie, M. G. L., and Spurk, M.: Subfossil European bog oaks: population dynamics and long-term growth depressions as indicators of changes in the Holocene hydro-regime and climate, Holocene, 12, 695-706, 2002.

Levanič, T., Popa, I., Poljanšek, S., and Nechita, C.: A 323-year long reconstruction of drought for SW Romania based on black pine (Pinus nigra) tree-ring widths, Int. J. Biometeorol., 57, 703714, https://doi.org/10.1007/s00484-012-0596-9, 2013.

Ljungqvist, F. C., Krusic, P. J., Sundqvist, H. S., Zorita, E., Brattström, G., and Frank, D.: Northern Hemisphere hydroclimate variability over the past twelve centuries, Nature, 532, 94111, https://doi.org/10.1038/nature17418, 2016.

Mann, M. E., Zhang, Z., Rutherford, S., Bradley, R. S., Hughes, M. K., Shindell, D., Ammann, C., Faluvegi, G., and Ni, F.: Global signatures and dynamical origins of the Little Ice Age and Medieval Climate Anomaly, Science, 326, 1256-1260, 2009.

MathWorks: MATLAB - The language of technical computing, 6.5th Edn., 1994-2008.

McCarroll, D., Young, Giles H. F., and Loader, N. J.: Measuring the skill of variance-scaled climate reconstructions and a test for the capture of extremes, Holocene, 25, 618-626, https://doi.org/10.1177/0959683614565956, 2015.

Pauling, A., Luterbacher, J., Casty, C., and Wanner, H.: Five hundred years of gridded high-resolution precipitation reconstructions over Europe and the connection to large-scale circulation, Clim. Dynam., 26, 387-405, https://doi.org/10.1007/s00382005-0090-8, 2006.

Pechtl, J. and Land, A.: Tree rings as a proxy for seasonal precipitation variability and Early Neolithic settlement dynamics in Bavaria, Germany, PLoS ONE, 14, e0210438, https://doi.org/10.1371/journal.pone.0210438, 2019.

Prokop, O., Koláŕ, T., Büntgen, U., Kyncl, J., Kyncl, T., Bošeł, M., Choma, M., Barta, P., and Rybníček, M.: On the palaeoclimatic potential of a millennium-long oak ring width chronology from Slovakia, Dendrochronologia, 40, 93-101, https://doi.org/10.1016/j.dendro.2016.08.001, 2016.

Ruiz-Labourdette, D., Génova, M., Schmitz, M. F., Urrutia, R., and Pineda, F. D.: Summer rainfall variability in European Mediterranean mountains from the sixteenth to the twentieth century reconstructed from tree rings, Int. J. Biometeorol., 58, 1627-1639, https://doi.org/10.1007/s00484-013-0766-4, 2014.

Schönbein, J.: Zur Rekonstruktion von Hochwasserereignissen in Europa aus holzanatomischen Parametern und historischen Quellen, Dissertation, Institut für Physische Georgrafie, Universität Freiburg, Freiburg, 94 pp., 2011.

Schönbein, J., Land, A., Friedrich, M., Glaser, R., and Küppers, M.: Seasonal reconstruction of summer precipitation variability and dating of flood events for the millennium between 3250 and 
2250 years BC for the Main Region, southern Germany, in: Integrated Analysis of Interglacial Climate Dynamics (INTERDYNAMIC), edited by: Schulz, M. and Paul, A., SpringerBriefs in Earth System Sciences, Springer International Publishing, Cham, 127-131, 2015.

Seftigen, K., Goosse, H., Klein, F., and Chen, D.: Hydroclimate variability in Scandinavia over the last millennium - insights from a climate model-proxy data comparison, Clim. Past, 13, 1831-1850, https://doi.org/10.5194/cp-13-1831-2017, 2017.

Spurk, M., Leuschner, H. H., Baillie, M. G. L., Briffa, K. R., and Friedrich, M.: Depositional frequency of German subfossil oaks: Climatically and non-climatically induced fluctuations in the Holocene, Holocene, 12, 707-715, https://doi.org/10.1191/0959683602hl583rp, 2002.

Steger, O.: Zur Eichenwicklerbekämpfung 1958 im Hochspessart, Forstwissenschafltiches Centralblatt, 78, 108-120, 1959.

Steger, O.: Spätfröste und Massenwechsel von Tortrix viridiana L. (Lep. Tortr.), Z. Angew. Entomol., 46, 213-216, 1960.

Stocker, T. F., Qin, D., Plattner, G.-K., Tignor, M., Allen, S. K., Boschung, J., Nauels, A., Xia, Y., Bex, V., and Midgley P. M. (Eds.): IPCC 2013: Climate Change 2013: The Physical Basis. Contribution of Working Group I to the Fifth Assessment Report of the Intergovernmental Panel on Climate Change, Cambridge University Press, United Kingdom and New York, NY, USA, 1535 pp., 2013.

Stockton, C. W. and Meko, D. M.: A long-term history of drought occurrence in western United States as inferred from tree rings, Weatherwise, 28, 244-249, 1975.

von Storch, H., Zorita, E., Jones, J. M., Dimitriev, Y., GonzálezRouco, F., and Tett, S. F. B.: Reconstructing past climate from noisy data, Science, 306, 679-682, 2004.
Wigley, T. M. L., Briffa, K. R., and Jones, P. D.: On the average value of correlated time series, with applications in dendroclimatology and hydrometeorology, J. Clim. Appl. Meteorol., 23, 201-213, 1984.

Wilson, R. and Elling, W.: Temporal instability in treegrowth/climate response in the Lower Bavarian Forest region: implications for dendroclimatic reconstruction, Trees-Struct. Funct., 18, 19-28, https://doi.org/10.1007/s00468-003-0273-z, 2004.

Wilson, R., Miles, D., Loader, N. J., Melvin, T., Cunningham, L., Cooper, R., and Briffa, K.: A millennial long March-July precipitation recontruction for southern-central England, Clim. Dynam., 40, 997-1017, https://doi.org/10.1007/s00382-012-1318z, 2013.

Wilson, R., Anchukaitis, K., Briffa, K. R., Büntgen, U., Cook, E., D’Arrigo, R., Davi, N., Esper, J., Frank, D., Gunnarson, B., Hegerl, G., Helama, S., Klesse, S., Krusic, P. J., Linderholm, H. W., Myglan, V., Osborn, T. J., Rydval, M., Schneider, L., Schurer, A., Wiles, G., Zhang, P., and Zorita, E.: Last millennium northern hemisphere summer temperatures from tree rings: Part I: The long term context, Quaternary Sci. Rev., 134, 1-18, https://doi.org/10.1016/j.quascirev.2015.12.005, 2016.

Wilson, R. J. S., Luckman, B. H., and Esper, J.: A 500 year dendroclimatic reconstruction of spring-summer precipitation from the lower Bavarian Forest region, Germany, Int. J. Climatol., 25, 611-630, https://doi.org/10.1002/joc.1150, 2005. 